\title{
Calculating sediment trapping efficiency for Reservoirs in series
}

\author{
$\underline{\text { D.K. Waters }}^{\text {a }}$ and S.E Lewis ${ }^{b}$ \\ ${ }^{a}$ Department of Natural Resources and Mines, Toowoomba, Queensland 4350, Australia \\ ${ }^{b}$ Centre for Tropical Water and Aquatic Ecosystem Research (TropWATER), James Cook University, \\ Townsville 4811 \\ Email: david.waters@dnrm.qld.gov.au
}

\begin{abstract}
Trapping Efficiency (TE) is defined as the proportion of inflowing sediment that is accumulated in a reservoir. Accurately predicting the trapping efficiency (TE) of sediment in reservoirs is critical to estimate their useful life and inform catchment models for sediment budget estimation. A daily formulation of the Churchill sediment trapping efficiency equation previously implemented in the eWater Source modelling framework, enables the user to account for the accumulation of sediment and hence the subsequent sediment yield exiting a reservoir. Where reservoirs are in series, the particle size of sediment passing through an upstream storage is generally finer than the 'local' sediment. Therefore, the application of the Churchill equation to each reservoir in isolation, not taking into account the different sources of sediment, may result in an under prediction of the sediment yield for a basin. Churchill (1948) proposed a method to account for sediment that had already passed through an upstream reservoir.
\end{abstract}

The original daily Churchill equation was applied to all storages and compared to a modified Churchill equation, applied to upstream reservoirs for three scenarios across the Great Barrier Reef (GBR), Namely: 1. The Pioneer River in the Mackay Whitsunday region which contains three small weirs $(<10,000 \mathrm{ML}) ; 2$. The Burnett River in the Southern GBR which contains three large upstream storages that flow into a reservoir in the lower reaches of the catchment and; 3. The proposed Hell's Gate Dam to be constructed on the Burdekin River upstream of the Burdekin Falls Dam.

The results showed negligible differences for the small storages and indicated that the application of TE models for such storages is probably redundant. Larger differences in sediment loads were calculated with the application of both TE models for the larger storages which demonstrate its usefulness to incorporate into future modelling. The scenarios also demonstrate the usefulness of models to quickly forecast the influence of proposed new reservoirs (or the modification of existing reservoirs) on sediment loads.

This paper will describe the modified Churchill approach and provide estimates of sediment yield with and without the modification and recommend where the curves are appropriate to be used in the GBR. The approach will also provide a method to improve estimates of sediment yield from basins where reservoirs are in series.

Keywords: $\quad$ eWater Source, Churchill, trapping efficiency, sediment yield 


\section{INTRODUCTION}

Accurately predicting the trapping efficiency (TE) of sediment in reservoirs is critical to predict their useful life and inform catchment models. Numerous methods are available from the simple empirical equations of Brown (1943), Churchill (1948) and Brune (1953) to models of increasing sophistication (see Verstraeten and Poesen, 2000). Researchers prefer the simple equations to calculate TE (in particular the Brune and Churchill curves) due to the speed of calculation, the limited input data required and, in many cases, they have proven to provide a reasonable estimate of TE (Borland, 1971; Verstraeten and Poesen, 2000; Espinosa-Villegas and Schnoor, 2009). The work shows that a daily trapping formulation of the Churchill (1948) curve can provide reliable estimations of TE (Lewis et al., 2013). While the Churchill (1948) curve for 'local silt' has been widely applied to reliably predict TE, to our knowledge there has been limited application of the Churchill (1948) curve for 'fine silt discharged from an upstream reservoir' (hereafter called sediment overflow reservoir curve).

Lewis et al. (2013) showed that for the Burdekin Falls Dam, northeastern Australia, a modified version of Churchill's 'local silt' equation formulated on a daily scale reliably predicted annual TE for the Dam. This modified equation was incorporated into the Source framework to model sediment loads across the basins of the GBR catchment area (Waters et al., 2014). The model appears to underestimate sediment loads delivered from certain basins which contain multiple reservoirs along the same stream network. This load underestimation may be the result of an overestimation of TE where a portion of flow and sediment has passed through an upstream reservoir. This study modifies the Churchill (1948) sediment overflow reservoir curve to a daily time step and demonstrates the use of both the upstream reservoir and the local silt curves to capture the proportion of sediment delivered from an upstream reservoir. We have used the equation from EspinosaVillegas and Schnoor (2009) for the local silt curve and developed an equation to best fit the sediment overflow reservoir curve. We demonstrate the method in three basins with variable reservoir configurations.

\section{BACKGROUND}

\section{1. eWater Source Modelling of storages}

The Great Barrier Reef (GBR) catchment area covers a large geographical extent from Cape York in North Queensland to the Mary Catchment in the South, an area of approximately 423,000 $\mathrm{km}^{2}$ (Figure 1). There are 35 major basins that drain to the GBR lagoon. Water storages are a dominant feature across the GBR basins in particular in regulated irrigation areas such as the Burnett River, the Fitzroy River, the Pioneer River and the Burdekin River Basins. This study has chosen reservoirs of different volumes which exist in a sequence along a stream network to examine the influence of the application of the upstream sediment overflow reservoir curve (where applicable) on sediment load in comparison to the current Source Catchments modelling approach where the local silt curve is applied across all sizable reservoirs. Three contrasting scenarios were selected:

1. Three small capacity nested weirs approximately $15 \mathrm{~km}$ apart in the wetter Pioneer River basin namely: Mirani (4,660 ML), Marian (3,980 ML) and Dumbleton (8,840 ML) Weirs (Figure 1a; Table 1).

2. A series of dams in the drier Burnett region were chosen including Bjelke-Petersen Dam (135,220 ML), Boondooma Dam (204,200 ML), Wuruma Dam (165,000ML) all draining to Paradise Dam (297,460 $\mathrm{ML}$ ) in the lower reaches of the Burnett River (Figure 1b; Table 1).

3. Hell's Gate is a proposed dam site in the upper reaches of the Burdekin River catchment approximately $200 \mathrm{~km}$ upstream of Burdekin Falls Dam (1.8 x 106 ML) on the Burdekin River (Figure 1c, Table 1). Two scenarios were modelled for the theoretical Hell's Gate Dam based on capacity estimates of proposed wall heights provided in Burrows (1999) including 970,000 ML and 5.72 x 106 ML.

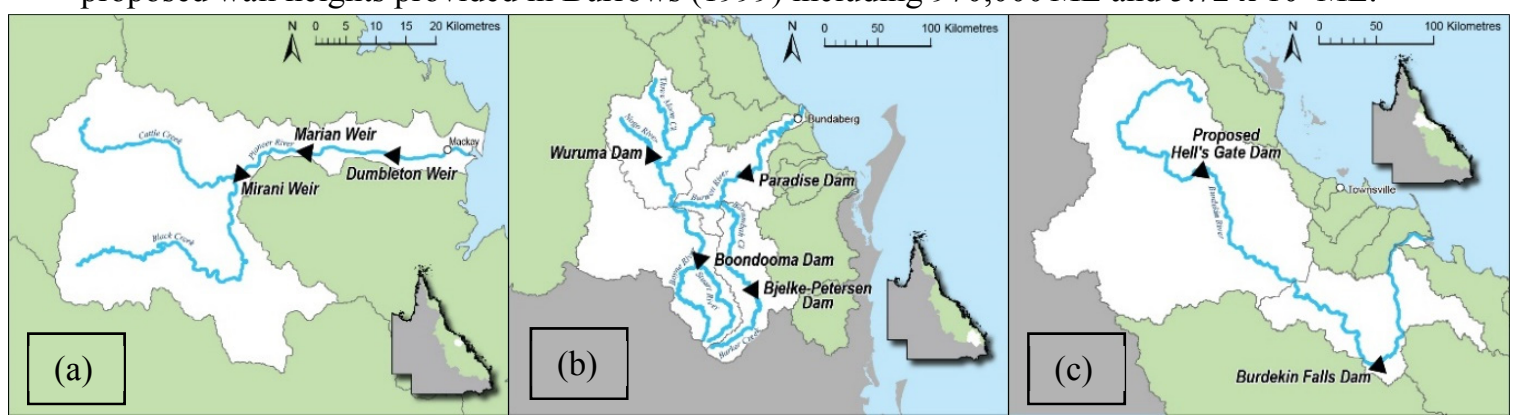

Figure 1. Reservoir locations for the three scenarios (a) Pioneer River Basin (b) Burnett River Basin (c) Burdekin River Basin. 
Waters D.K., and Lewis S.E., Calculating sediment trapping efficiency for reservoirs in series

Table 1. Details of the reservoirs/scenarios modelled in this study including the key parameters required to calculate the Sedimentation Index for the Churchill equation (with exception of daily inflow).

\begin{tabular}{|c|c|c|c|c|c|}
\hline Basin & Dam/weir & Capacity (ML) & Length (m) & Drainage area $\left(\mathrm{km}^{2}\right)$ & Curves used \\
\hline \multirow[t]{2}{*}{ Pioneer } & Mirani & 3,980 & 315 & 1,211 & Local \\
\hline & Marian & 4,600 & 6,209 & 1,381 & Local and Upstream \\
\hline \multirow[t]{3}{*}{ Burnett } & Wuruma & 164,005 & 13,900 & 2,320 & Local \\
\hline & Boondooma & 204,200 & 40,260 & 4,040 & Local \\
\hline & Paradise & 297,463 & 45,000 & 30,590 & Local and Upstream \\
\hline \multirow[t]{2}{*}{ Burdekin } & Hell's Gate $^{1}$ & 970,000 & 40,000 & 17,750 & Local \\
\hline & Hell's Gate $^{2}$ & $5,720,000$ & 70,000 & 17,750 & Local \\
\hline
\end{tabular}

\subsection{Trapping efficiency and the development of the sediment overflow reservoir curve}

Trapping Efficiency (TE) is defined as the percentage of inflowing sediment that is retained in a reservoir. Researchers in the USA highlighted the strong correlation between measured TE and reservoir-catchment characteristics including the reservoir capacity to watershed area ratio (Brown, 1943), the reservoir capacity to annual inflow ratio (Brune 1953) and the capacity to inflow ratio coupled with average stream velocity (Churchill, 1948), all of which require limited input data and have been used to estimate TE where measurements are not available. A number of studies (e.g. Borland, 1971; Trimble and Bube, 1990; Verstraeten and Poesen, 2000; Espinosa-Villegas and Schnoor, 2009) prefer the Churchill local silt curve as it provides an 'effective residence time' and has, in many cases, provided the most reliable estimates of TE. Lewis et al. (2013) demonstrated that a daily formulation of the Churchill local silt curve reasonably predicted annual TE across a number of reservoirs with different inflow characteristics. Churchill (1948) presented a curve defining the TE of sediment that has passed through an upstream reservoir. Both Churchill curves are defined by the reservoir Sedimentation Index (SI) which is calculated by:

$$
S I=\frac{9.61 \times 10^{6} \tau}{u}
$$

Where the constant, $9.61 \times 10^{6}$ represents a conversion from years to seconds and metres to feet to meet the requirements of the Espinosa-Villegas and Schnoor (2009) equation; $\tau$ is the residence time (in years) calculated as $V / Q$ where $V$ is the reservoir capacity volume $\left(\mathrm{m}^{3}\right)$ and $Q$ is the mean annual inflow $\left(\mathrm{m}^{3} \cdot \mathrm{y}^{-1}\right)$ and; $u$ is the mean annual velocity of the inflow (in $\mathrm{ms}^{-1}$ ) which is expressed as

$$
u=\frac{3.17 \times 10^{-8} Q}{A}
$$

Where the constant, $3.17 \times 10^{-8}$ represents a conversion between inflow per year to inflow per second and $A$ is the cross-sectional area of the reservoir $\left(\right.$ in $\left.\mathrm{m}^{2}\right)$ which is calculated by $V / L(L=$ the length of the reservoir measured from the dam wall to the most upstream impounded water at dam capacity in $\mathrm{m}$ ).

A number of attempts have been made to produce a 'best fit' equation for the Churchill local silt curve (data from Churchill, (1948), Borland, (1971), Trimble and Bube (1990) and the U.S. Army Corps of Engineers (1995); were presented in Espinosa-Villegas and Schnoor (2009)). We have used the equation presented in Lewis et al. (2013) which was modified from Espinosa-Villegas and Schnoor (2009) for the 'local silt' curve (Figure 2).

The sediment overflow reservoir curve produced by Churchill (1948) was reproduced by reading each SI value and the corresponding 'percent of incoming silt passing through reservoir' values off the original plot and fitting a logarithmic trend line through the data points to give an equation which best matched the original curve (see sediment overflow curve 1 and equation in Figure 2). However, the projection of this curve (curve 1) beyond an SI value of $1 \times 10^{8}$ would result in this curve intersecting and crossing the local silt curve which is not desirable as a higher TE should always be expected for the local silt curve for the same SI value (until a value of $0 \%$ or $100 \%$ is reached in both curves) (see also Trimble and Bube, 1990). Indeed, no measured TE data are available (that we know of) to inform the sediment overflow reservoir curve beyond an SI value of $\sim 1$ $\times 10^{8}$ (Figure 2) and hence the extrapolation of the curve beyond this point is problematic. Hence to overcome the issue of the two curves intersecting a second logarithmic equation was produced to be applied where SI values exceed $1 \times 10^{8}$ (see sediment overflow curve 2 and associated equation in Figure 2). This second curve was designed to run roughly parallel to the local silt curve. 


\subsection{Scenarios}

The daily sediment loads produced by the Source Catchments model for reservoirs plus daily streamflow, reservoir capacity and length were all used to calculate the SI and TE for the two equations. Table 1 provides the details of the reservoirs and their key properties. The local silt equation was applied to the most upstream reservoir(s) which only receive local sediment inputs and the TE and resultant sediment load passing over that reservoir were calculated. For the downstream reservoirs that receive a combination of sediment derived from an upstream reservoir and local sediment source (i.e. new sediment delivered below the upstream reservoir), both the sediment overflow equations and local silt equation were used to calculate TE. Applying the different curves will result in much lower TE for the sediment sourced from the upstream reservoir.

The sum of the two outputs provides the total sediment passing through the downstream reservoir. For example, in Scenario 1 for the Pioneer River basin, the Churchill local silt TE was applied to Mirani Weir, then downstream at Marian Weir, the sediment overflow reservoir TE was applied to the outflow sediment load from the upstream Mirani Weir and the local silt TE was used for the sediment load that had entered the stream network below Mirani Weir (this 'new/local' sediment load was calculated as the difference between the total sediment entering Marian Weir from the sediment load that had passed through the Mirani Weir upstream). Similarly for the final weir at Dumbleton, the sediment overflow reservoir equation was applied to the outflow sediment load from the upstream storage, Marian and the local sediment load (difference between the upstream sediment load and the incoming sediment load to Dumbleton) had the local silt TE curve applied. We note that the sediment load input data can be derived through either monitoring or modelling or a combination of the two and then multiplied by their respective TE (in percent) to calculate the amount of sediment trapped in (and amount passing over) the downstream reservoir. To examine the influence of the sediment overflow reservoir equation on total sediment loads we compared these outputs to the sediment load derived exclusively using the local silt curve on all reservoirs (i.e. the current method employed by the Source Catchments model).

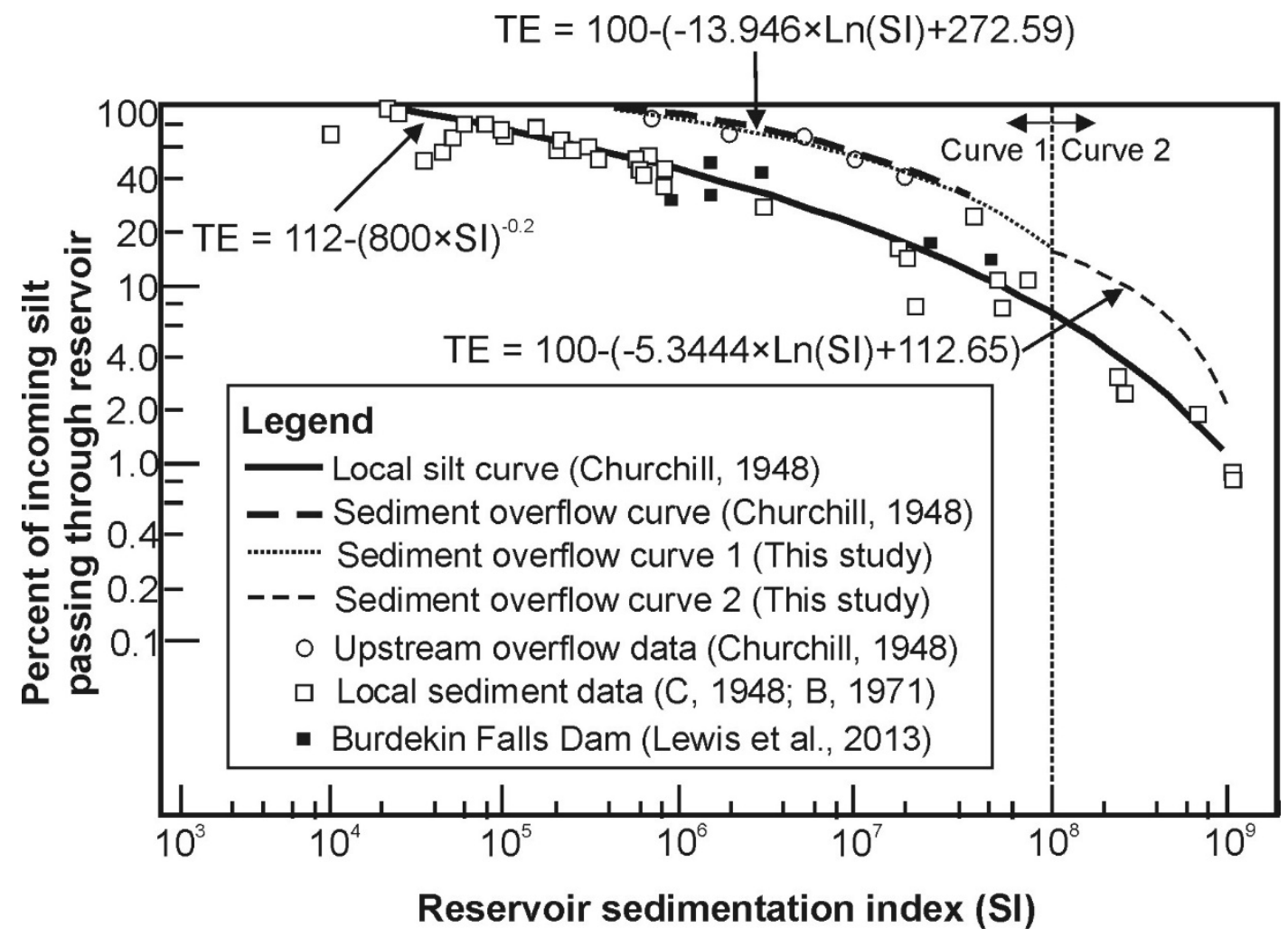

Figure 2. Original Churchill curves with measured data from Churchill (C; 1948), Borland (B; 1971) and Lewis (2013) and the resultant TE equations fitted to the measured data.

In large river networks, the travel time of water and associated sediment from one reservoir to the next may take several days (to weeks in extreme cases) and hence a residence time factor may need to be applied where both TE curves are required. In this study, the peak flows in the river hydrographs at both upstream reservoir and downstream reservoir locations were compared to provide an estimate of travel time between reservoirs. For the Pioneer River case study, the residence time was $<1$ day and so for our daily modelling no adjustment was required. The Burnett River case study was complicated by the number of upstream dams in different parts of the catchment and the time-lag differences in rainfall-runoff sources and hence we chose not to apply a 
residence time factor. A three-day difference in the peak flows between the Hell's Gate site and Burdekin Falls was observed and hence applied in our model. We present the sediment loads exiting the final reservoir for different time periods. The Source Catchments models were run for the 3 basins over a 28 year period from July 1986 to June 2014. We present 1 . The mean annual load over this whole 28 -year timeframe, 2 . The mean annual load over a period that overlaps with available monitoring data and; 3 . Annual loads where major flow events occurred.

\section{RESULTS}

\subsection{Pioneer River Basin}

The results show little difference $(<2 \%)$ in the end-of-catchment sediment loads between the two trapping models: using the local silt equation only (mean annual load $132 \mathrm{kt}$ over the 28 year period) and with the application of both the local silt and sediment overflow reservoir equations (134 kt) (Table 2$)$ and if no trapping was applied at all $(137 \mathrm{kt})$. Little differences were also calculated between the two trapping models for the period where monitoring data are available (2006/07 to 2013/14) and in the large flows that occurred in the 2010/11 year (Table 2). There was a considerable difference between the modelled load outputs and the available monitoring data (Table 2).

\subsection{Burnett River Basin}

Similar to the Pioneer River Basin results, there was only a small difference $(4 \mathrm{kt})$ in the loads reported over the 28-year period between the two trapping models for the Burnett Basin scenario. There were larger differences between the two trapping models for the larger flow event years in 2010/11 (41 kt) and 2012/13 $(23 \mathrm{kt}$ ), although the load percentage difference was $<2 \%$ (Table 2$)$. The loads produced from both trapping models show close agreement with the monitoring data for the 2010/11 financial year, although both models considerably underestimated the monitored loads in the 2012/13 year (Table 2).

\subsection{Burdekin River Basin}

The difference between the two trapping models for the larger dam (and streamflow volumes) in the Burdekin River was greater in terms of both kt $(65 \mathrm{kt})$ and percent load difference $(\sim 7 \%)$ for the mean annual loads over the 28 year period for the Hell's Gate lower capacity (970,000 ML) scenario (Table 2). These differences reduced considerably under the higher capacity $\left(5.72 \times 10^{6} \mathrm{ML}\right)$ scenario $(26 \mathrm{kt}$ and $\sim 3 \%$ ) (Table 2$)$. The modelling in the 2008/09 year which had the highest peak flows over the 28 year timeframe showed larger differences between both kt (523 kt and $224 \mathrm{kt}$ for the lower and higher capacity scenarios, respectively) and percent difference ( $\sim 9 \%$ and $\sim 4 \%$, respectively) (Table 2$)$. Interestingly, the modelling also gave a guide about the amount of extra sediment that would be hypothetically trapped in the Hell's Gate Dam and the resultant reduction in loads through the Burdekin Falls Dam. Over the 28 year period, in the order of $283 \mathrm{kt}$ (lower capacity) to $364 \mathrm{kt}$ (higher capacity) per annum of extra sediment is predicted be trapped with the Hell's Gate Dam with the amount greatly increasing for individual years with higher stream flows (e.g. 2008/09 an extra $1,017 \mathrm{kt}$ and 1,686 kt would be trapped with the Hell's Gate dam under the lower and higher capacity scenarios, respectively).

Table 2. Comparison of load estimates over a range of time periods using the local and upstream curves, local curve only and estimated derived from monitored data.

\begin{tabular}{|l|l|c|c|c|}
\hline River/dam overflow & Time period & $\begin{array}{c}\text { Modelled TSS } \\
\text { load with both } \\
\text { TE curves } \\
\text { (kt/yr) }\end{array}$ & $\begin{array}{c}\text { Modelled } \\
\text { TSS load } \\
\text { with local } \\
\text { TE curve } \\
\text { only (kt/yr) }\end{array}$ & $\begin{array}{c}\text { Monitored } \\
\text { mean } \\
\text { annual load } \\
\text { (kt/yr) }\end{array}$ \\
\hline \hline \multirow{2}{*}{$\begin{array}{l}\text { Pioneer River at Dumbleton } \\
\text { overflow }\end{array}$} & $1986 / 87$ to $2013 / 14$ & 134 & 132 & N/A \\
\cline { 2 - 6 } & $2006 / 07$ to $2013 / 14$ & 188 & 186 & $261^{* *}$ \\
\cline { 2 - 6 } & $2010 / 11$ & 432 & 431 & $820^{* *}$ \\
\hline \hline \multirow{2}{*}{$\begin{array}{l}\text { Burnett River at Paradise Dam } \\
\text { overflow }\end{array}$} & $1986 / 87$ to $2013 / 14$ & 249 & 245 & N/A \\
\cline { 2 - 6 } & $2010 / 11$ & 2,631 & 2,590 & $2,600^{* *}$ \\
\cline { 2 - 6 } & $2012 / 13$ & 2,601 & 2,578 & $3,700^{* *}$ \\
\hline \hline
\end{tabular}


Waters D.K., and Lewis S.E., Calculating sediment trapping efficiency for reservoirs in series

\begin{tabular}{|l|l|c|c|c|}
\hline $\begin{array}{l}\text { Burdekin River at Burdekin Falls } \\
\text { Dam overflow }\end{array}$ & $2008 / 09$ & 6,359 & 5,836 & $7,376^{*}$ \\
\hline $\begin{array}{l}\text { Burdekin River at Burdekin Falls } \\
\text { Dam overflow }\end{array}$ & $1986 / 87$ to 2013/14 & 826 & 800 & $1,190^{*}$ \\
\cline { 2 - 5 } & $2008 / 09$ & 5,690 & 5,466 & $7,376^{*}$ \\
\hline
\end{tabular}

${ }^{I}$ Hell's Gate capacity $=970,000 \mathrm{ML} ;{ }^{2}$ Hell's Gate capacity $=5,720,000 \mathrm{ML} ;{ }^{*}$ Current modelled loads (i.e. without Hell's Gate Dam from Dougall et al. 2014). **From GBR Loads Monitoring Program

\section{DISCUSSION}

\subsection{TE Curves and equations}

To our knowledge, this is the first application of both Churchill's (1948) local silt and sediment overflow reservoir curves modified for daily time intervals to model sediment TE outside of the Tennessee River basin. No additional data have been produced to better constrain the sediment overflow reservoir curve and this is an area of future research. Trimble and Bube (1990) examined a number of 'best fit' options to both the local silt and sediment overflow reservoir curves, although their process was complicated and their 'revised curves' were somewhat different to the original Churchill curves (see Figures 8 and 9 in Trimble and Bube, 1990). The equations developed in this study were designed to best match the original Churchill (1948) curves with the additional equation for the sediment overflow reservoir curve to be applied for SI values $>1 \times 10^{8}$ so that the local silt and sediment overflow reservoir curves do not intersect. Additional measured TE data for SI $>2 \times$ $10^{7}$ for upstream reservoirs may allow for a single equation to be developed. In any case, the difference between the equations developed in this study and in Trimble and Bube (1990) to define both TE curves are unlikely to produce large differences in catchment sediment load budgets.

There is also a need to collect additional measured TE data relevant to the catchments of the GBR to demonstrate the utility of the Churchill (1948) curves in this region. Presently only five years of measured TE data from one reservoir, the Burdekin Falls Dam have been used to 'validate' the local silt curve (Lewis et al., 2013). The outputs from the model scenario runs in this study provide important insights on modelling sediment loads to the GBR, which are discussed further below.

\subsection{TE of small storages $<10,000 \mathrm{ML}$}

The Pioneer Basin scenario was designed to examine the influence of nested reservoirs, of relatively small capacity $(<10,000 \mathrm{ML})$, on the transport of sediment loads to the GBR. In this case, the differences between the amount of trapping between the two models and with the no trapping scenario were all negligible in terms of both load and percent difference in load. Hence, the model outputs show that small storages on relatively large rivers do little to trap sediment. Referring to Figure 2, the SI values were $<1.5 \times 10^{4}$ during most significant flows in the Pioneer River, which is equivalent to $0 \%$ trapping for both the local silt and sediment overflow reservoir curves. Indeed, this finding provides justification for the exclusion of the use of Churchill curves for small storages $<10,000 \mathrm{ML}$ in the Source Catchments modelling.

\subsection{TE of larger storages $>100,000 \mathrm{ML}$}

The Burnett Basin scenario was designed to examine the influence of the combined sediment overflow reservoir and local silt equations on the sediment loads in comparison to the current Source Catchments modelling approach of only applying the local silt equation across all reservoirs. While the logic might imply that the largest percent differences in the modelled loads would occur in the years where the largest flow events occurred in the basin, in fact it was found that the intermediate flow years such as 1995/96 (data not presented), produced the greatest percentage difference in loads for the Burnett Basin scenario. Indeed, a review of the raw data showed that in this scenario the SI values during the larger runoff events (i.e. when most sediment is being transported) in 1995/96 were largely between $1.0 \times 10^{6}$ and $2.0 \times 10^{7}$ which coincides with the largest difference in TE between the two curves (see Figure 2). While the percentage difference in TSS load between the two trapping models was relatively low $(<2.1 \%)$, the differences in sediment mass (up to $41 \mathrm{kt}$ in the 2010/11 year) are considerable when estimating loads and targeting load reductions

\subsection{TE of large storages $>1,000,000 \mathrm{ML}$}

The Burdekin Basin scenario was designed to demonstrate the ability of this model to predict the influence of the proposed 'Hell's Gate' Dam on the TE and sediment loads exported through the Burdekin Falls Dam. Interestingly, in the lower capacity $(970,000 \mathrm{ML})$ scenario, it was the larger flow events in the Burdekin River that resulted in the largest percentage difference $(\sim 9 \%)$ between the loads calculated with the application of 
Waters D.K., and Lewis S.E., Calculating sediment trapping efficiency for reservoirs in series

both dam models and only the local silt equation, while the difference for the same year (2008/09) is greatly reduced $(\sim 4 \%)$ under the larger capacity scenario. Importantly, this simple modelling approach allows different scenarios to be quickly modelled such as changes in dam capacity or spillway configuration. In that regard, the theoretical reduction of sediment transported through the Burdekin Falls Dam of $\sim 300 \mathrm{kt}$ with the construction of the Hell's Gate Dam is equivalent to $\sim 10 \%$ of the long-term mean annual sediment export from the Burdekin River. In years with larger flows, up to $2 \mathrm{Mt}$ of sediment could potentially be trapped in this system.

\section{CONCLUSION}

In this study, we developed a new TE modelling approach based on the Churchill (1948) local silt and sediment overflow reservoir curves for incorporation into the Source Catchments modelling framework. Three scenarios were examined for small, larger and very large (hypothetical) reservoirs. The results showed negligible differences for the small storages and indicated that the application of TE models for such storages is probably redundant. Larger differences in sediment loads were calculated with the application of both TE models for the larger storages which demonstrate its usefulness to incorporate in future models. The scenarios also demonstrated the value of models to quickly forecast the influence of proposed new reservoirs on sediment loads. The model scenarios presented in this study show that in all cases where a discrepancy between the model outputs and monitoring data occurred, that the potential overestimation of TE was not a factor to explain the differences in sediment loads. While more local and internationally derived TE data are required to better constrain both Churchill (1948) curves as well as incorporating uncertainty in the measured datasets, our approach provides a way forward to incorporate both the local silt and sediment overflow reservoir equations into catchment modelling exercises.

\section{REFERENCES}

Borland, W.M. (1971). Reservoir sedimentation, in River mechanics Vol II, edited by H.W. Shen, pp. 29.129.38, Colorado State University, Fort Collins, CO.

Brown, C.B. (1943). Discussion of sedimentation in reservoirs, by B.J. Witzig, Proceedings of the American Society of Civil Engineers, 69, 1493-1500.

Brune, G.M. (1953). Trap efficiency of reservoirs, Trans. of the American Geophysical Union, 34, 407-418.

Burrows, D. W. (1999). An initial environmental assessment of water infrastructure options in the Burdekin catchment. Australian Centre for Tropical Freshwater Research Report 99/29, James Cook University, Townsville, QLD, Australia.

Churchill, M.A. (1948). Discussion of “Analyses and use of reservoir sedimentation data” by L.C. Gottschalk. Federal Inter-agency Sedimentation Conf Proc, Denver, Colorado, Washington DC, US Geol. Survey, 139140.

Espinosa-Villegas, C.O., and J.L. Schnoor (2009). Comparison of long-term observed sediment trap efficiency with empirical equations for Coralville Reservoir, Iowa, Journal of Environmental Engineering, 135, 518-525.

Lewis, S.E. Bainbridge, Z.T. Kuhnert, P.M. Sherman, B.S. Henderson, B. Dougall, C. Cooper, M. Brodie, J.E. (2013). Calculating sediment trapping efficiencies for reservoirs in tropical settings: a case study from the Burdekin Falls Dam, NE Australia. Water Resources Research 49, 1017-1029.

Trimble, S.W., \& K.P. Bube (1990). Improved reservoir trap efficiency prediction. The Env. Prof, 12, 255-272.

U.S. Army Corps of Engineers. (1995). Engineering and design: Sedimentation investigations of rivers and reservoirs, Washington, D.C.

Verstraeten, G., and J. Poesen (2000). Estimating trap efficiency of small reservoirs and ponds: methods and implications for the assessment of sediment yield, Progress in Physical Geography, 24, 219-251.

Waters, D.K., Carroll, C., Ellis, R., Hateley, L., McCloskey, G.L., Packett, R., Dougall, C. and Fentie, B. (2014). Modelling reductions of pollutant loads due to improved management practices in the Great Barrier Reef catchments-Whole of GBR. Queensland Department of Natural Resources and Mines, Toowoomba, Australia. 